\title{
Effectiveness of structured teaching programme regarding prevention and control of methicillin- resistant Staphylococcus aureus on nurses' knowledge and attitude in Egypt
}

\begin{abstract}
Background: Because of rapid occurrence and ever-mutating attributes of MRSA infection that makes it difficult to detect and manage. Therefore, nurses need to be knowledgeable of MRSA.
\end{abstract}

Aim: To assess the effectiveness of structured teaching programmer on knowledge and attitude regarding prevention and control of Methicillin-Resistant Staphylococcus aureus among medical-surgical and ICU nurses in Egypt.

Material and Method: Pre/ post-quasi-experimental study design was conducted over a period of six months consisted of a random sample of 60 nurses worked in critical and medical-surgical settings at Al Manial university hospital in Egypt. Pre/post Knowledge and attitude questionnaires regarding MRSA were constructed by the researchers and their validity was examined by a panel of experts. Data was gathered and analyzed utilizing descriptive and inferential statistical tests.

Results: The findings revealed the significant increase in nurses' knowledge after teaching program regarding definition, risk factors, pathogenesis, prevention, and treatment. Moreover, nurses' showed significant improvements in the attitude towards prevention and control of MRSA infection after exposure to educational program but showed no change regarding the concern of the workload affects their abilities to apply infection prevention guidelines and they still feel with danger when contacting with MRSA patients and they see that they should spend little time with MRSA patient.

Conclusion: There was an improvement in nurses' knowledge and attitude responses regarding MRSA control and prevention after exposure to the educational programme.

Recommendations: Develop and implement nurses' practical guidelines to prevent and control MRSA infection in a different health care setting.

Keywords: Nurses, knowledge, attitude, MRSA, structured programme

\section{Introduction}

Staphylococci bacteria are normal skin flora found mostly on the skin and nose of some healthy people. They are typically harmless but become harmful if they enter the bloodstream through a breakdown in the skin integrity. Staphylococcus Aurous is the most prevalent species of staphylococcus that pass through the skin and induce staphylococcal infections. Methicillin-Resistant Staphylococcus aureus (MRSA) is a kind of Staphylococcus bacteria that is resistant to beta-lactams antibiotics such as amoxicillin, penicillin, and Oxacillin (CDC) [1]. The resistance may expand to similar antibiotics making this pathogenic organism hard to treat (Banning M) [2]. Moreover, MRSA infection is well transmitted through direct contact of the skin notably contact with open wounds and spreads to the deeper tissues, then travel further into the bloodstream causing bacteremia ( CDC \& Su C, et al.) [1,3]. As well, MRSA can be spread through indirect contact with infected objects like towels, bed linens and blankets (Biboh H.) [4]. As a result of the resistance of the infection to prescribed antibiotics and the effect on patient's decreased immunity, additional preventive measures concerns for patients has greatly enlarged throughout the past few years( Banning M \& Gloud D) [2,5].
NNahla Shaaban Khalii*1 and Asmaa Diab AbdelFattah Hassan ${ }^{2}$

${ }^{1}$ Critical Care Nursing Department, Faculty of Nursing, Cairo University, Egypt ${ }^{2}$ Medical Surgical Nursing Department, Faculty of Nursing, Cairo University, Egypt

*Author for correspondence:

nahlakhalil28@yahoo.com 
Occurrence and spread of MRSA can be prevented by surveillance and screening of admitted patients, healthcare personnel screening, isolation units, protective clothing (Lindberg M) [6] and disinfection of any equipment come into the patient's room (Matouskova I) [7]. Furthermore, WHO [8] recommends practicing hand wash to be one of the most necessary preventative measures to potentiate the prevention of MRSA infection. Because of rapid incidence and ever-mutating characteristics of MRSA infection that makes it difficult to explore and manage, bedside nurses need to be knowledgeable of MRSA route of transmission, as well as contact precautions to make sure the protection of patients, their care providers, and visitors. (Rohde R.) [9]. So, health care providers have a significant role in the prevention of MRSA transmission in numerous healthcare settings. The knowledge acquired by health care providers about MRSA has a great effect on their attitude to regularly take preventive measures in the direction of reducing MRSA infection (Seibert D, et al)

[10]. As well, according to Easton PM et al., [11] nearly $80 \%$ of healthcare providers need information and education within their work areas. Moreover, Trigg D et al., [12] stated that if the nursing staff does not be aware of existing MRSA policy, a spread of MRSA infection would increase due to inadequate knowledge. To improve the attitude of nurses toward following protective measures in reducing MRSA infection in hospitals, they must be aware and have adequate knowledge about MRSA infection and its control measures. Nurses have an essential role in the prevention of MRSA transmission in different healthcare settings. The knowledge gained and perceived by nurses about MRSA has a tremendous effect on their attitude to continuously take preventive measures towards decreasing healthcare-associated MRSA ( Seibert D, et al ) [10].

It has been documented in several previous studies that healthcare team members like physicians and nurses are accountable for the transmission of nosocomial infections. An extensive Literature review has explored the knowledge and practices of nurses are limited. Therefore, the current study was conducted to assess the effectiveness of structured teaching programme on knowledge and attitude regarding prevention and control of MethicillinResistant Staphylococcus aureus among nurses At AL Manial university Hospital in Egypt.

\section{- The significance of the study}

Prevalence of MRSA demanding tremendous economic costs on patients and hospitals (Klein E et al.) [13]. The duration of hospitalization stay for MRSA infection is approximately twice that of another type of stay, 10 days compared to 4.6 days respectively (Esther $s$ et al) [14]. Therefore, infection prevention is a principal aspect needed for patient safety and quality of care within the clinical settings to avoid the prevalence of MRSA infection (Gloud D) [5]. The findings from this study can augment the present literature and may be utilized in developing interventions to reduce the spread of infections in healthcare settings. To the best of our knowledge, this is the first study which focuses on conduction of educational program regarding MRSA infection and its prevention in collaboration with infection control unit at $\mathrm{Al}$ Manial university hospital in Egypt.

\section{- The aim of the study}

This study aimed to evaluate the effectiveness of a structured education programme on knowledge and attitude regarding prevention and control of methicillin-resistant Staphylococcus aureus among nurses at $\mathrm{Al}$ Manial University Hospital in Egypt.

\section{Hypothesis}

To achieve the aim, the following hypotheses were stated and tested at 0.05 level of significance:

\section{- H1}

Mean post-test knowledge score of staff nurses who received structured teaching programme regarding MRSA control and prevention will be significantly higher than the mean pre-test knowledge score

\section{$\square \mathbf{H 2}$}

Nurses' attitude towards MRSA infection control and prevention after a structured teaching programme show greater improvement than before the program.

\section{Subjects and Methods}

\section{- Study design}

This was a pre/post-quasi-experimental design study.

\section{Samples and setting}

The target population was nurses from 
different departments at al Manial university hospital including Intensive Care Unit (ICU) Coronary Care Unit (CCU), Emergency critical care unit (ECCU), and non-critical care units including medical and surgical wards. Sample Size was calculated depending on the following measurements; margin error was 5\%, the confidence interval was $95 \%$, population size obtained was 300. Sixty nurses were chosen randomly from the list of the registered nurses. Nurses working in the outpatient departments were excluded from the study because they do not include direct contact with MRSA cases. The study was conducted during the period from January 2015 to July 2015.

\section{Data collection instruments}

Two instruments were utilized. The first instrument included two parts. The first part contained nurses' characteristics (age, sex, and educational level, an area of work/department and years of experience. The second part included MRSA knowledge questionnaire. Knowledge was assessed through 15 multiplechoice questions and 20 true/false questions with scores ranging from 0 to 35 (one point for each correct answer). The second instrument included the nurses' attitude towards MRSA infection that was evaluated through seven items using the Likert scale of 1 to 3, with 3 being "agree" 2, being neutral, and 1 being "disagree".

\section{Validity and Reliability}

Test-retest reliability was carried out including ten nurses; two infection control nurses, two nurses working in a medical ward, two nurses working in the surgical ward, and four nurses working in emergency and intensive care critical care units. They were chosen randomly and answered the questionnaire twice with a two-week interval. The test-retest information on each question was analyzed using interclass correlation. For each item, the correlation coefficients ranged from 0.78-0.88 indicating that the knowledge and attitude questionnaire were reliable tools.

\section{Data collection procedure}

Formal written permission was obtained from the Medical-surgical and critical care setting at $\mathrm{Al}$ Manial University Hospital in Egypt. Data collection technique used was paper and pen test. On the first day (pre-test) 35-item knowledge questionnaire in the form of multiple choice and true/ false as well as seven items attitude questionnaire utilizing Likert scale were given to participants by the researchers. During which the purpose of the study was explained to all nurses. The duration of a pre/post-test and attitude questionnaire lasted one hour. The conduction of pretest for overall nurses lasted three weeks. Later, the planned structured program in the form of two sessions was conducted. The first session was two hours interactive lecture that covered definition, pathogenesis, clinical picture, and risk factors to MRSA. The second session (2 hours) was in the form of video-assisted instructions and role play simulation (2 hours) that covered the preventive and control measures of MRSA infection such as hand wash and contact precautions skills. Later, in the following week, knowledge post-test and attitude questionnaire were re-administrated. Overall data were collected from January 2015 to July 2015 for 60 nurses according to the planned time schedule of the researched clinical settings in the hospital.

\section{Pilot Study}

A pilot study was conducted on ten nurses to test the clarity of the questionnaires. Most of questionnaires items were clear except two items in the knowledge questionnaire were restated. Accordingly, the ten nurses were excluded from the study and the findings of the pilot study confirmed that the study was feasible.

\section{Ethical Considerations}

A copy of the covering letter including the attached questionnaire which provided information about the objective and nature of the research clarifying the anonymity of the results was sent to the nursing administrator of the hospital. Then, permission was granted to carry out the study. Later, a written consent form was signed by all the participants.

\section{Data Analysis}

Descriptive statistics were used such as frequencies, means, and standard deviations were used to summarize the data. On the other hand, inferential statistics were used such as t-test to assess the statistical significance of differences between nurses' knowledge scores before and after the educational program. While chi-square was used to examine differences in attitude before and after the educational program. Pearson's correlation coefficient was 
also used to examine potential correlations between knowledge scores, and selected nurses' characteristics.

\section{Results}

Of the sixty nurses, $93.3 \%$ were females. 35 $\%$ of the respondents their age ranged between 30 and 40 years with the mean age 33.68 years and they had 20-30 years of experience with the mean 13.20 years respectively. The nurses worked in a variety of settings. Half of them worked in acute care settings including ICU (25\%) and emergency critical care (25\%). Moreover, $43 \%$ of nurses worked in the surgical ward and $6.7 \%$ in the medical unit. Finally, more than two thirds (65\%) of nurses were secondary diploma graduates and the majority of them (85\%) worked full time (see TABLE 1).

Nearly two-thirds of the nurses made false answers in MRSA knowledge test regarding both risk factors (60.4\%) and prevention $(63 \%)$. Furthermore, more than half of nurses made false answers in the other items such as definition $(51.1 \%)$, methods of transmission (56.7\%), complications (52.2\%) and treatment (55\%) before participation in the educational program. While after completion of the program, the nurses demonstrated lower false answers and accordingly they obtained higher mean scores in all items of MRSA knowledge questionnaire such as definition (28.7 \%), methods of transmission $(34.0 \%)$ and risk factors $(35 \%)$, prevention $(28 \%)$ and treatment $(22.9 \%)$ after educational program. Accordingly, a statistically significant difference was found between pre and post- MRSA knowledge scores among nurses where $(\mathrm{t}=12.61 ; \mathrm{p}=0.00)$. As nurses obtained mean \pm SD $(14.91 \pm 5.1)$ in pre-test versus mean $\pm \mathrm{SD}(25.80 \pm 4.29)$ in post-test (TABLE 2$)$.

There was no significant statistical correlation between nurses' knowledge and nurses characteristics' before and after the educational program (TABLE 3). Regarding

\begin{tabular}{|c|c|c|}
\hline Variable & $\mathbf{N}$ & $\%$ \\
\hline \multicolumn{3}{|c|}{ Age } \\
\hline $18-30$ & 16 & 26.7 \\
\hline $31-40$ & 21 & 35.0 \\
\hline $41-50$ & 15 & 25.0 \\
\hline $51-60$ & 8 & 14.0 \\
\hline \multicolumn{3}{|c|}{ Mean and SD=33.68 \pm 9.67} \\
\hline \multicolumn{3}{|l|}{ Gender } \\
\hline Male & 4 & 6.7 \\
\hline Female & 56 & 93.3 \\
\hline \multicolumn{3}{|l|}{ Educational Level } \\
\hline Diploma & 39 & 65.0 \\
\hline Technical Institute & 15 & 25 \\
\hline Baccalaureate & 6 & 10.0 \\
\hline \multicolumn{3}{|c|}{ Years of Experience } \\
\hline $1-5$ & 7 & 11.7 \\
\hline 6-10 & 15 & 25.0 \\
\hline 11-19 & 14 & 23.3 \\
\hline $20-30$ & 18 & 30.0 \\
\hline Over 30 & 6 & 10.0 \\
\hline \multicolumn{3}{|c|}{ Mean and SD $=13.20 \pm 1.28$} \\
\hline \multicolumn{3}{|l|}{ Work type } \\
\hline Fulltime & 51 & 85.0 \\
\hline Part time & 9 & 15.0 \\
\hline \multicolumn{3}{|l|}{ Place of work } \\
\hline Surgical ward & 26 & 43.3 \\
\hline ICU & 15 & 25.0 \\
\hline Medical unit & 4 & 6.7 \\
\hline Emergency unit & 15 & 25.0 \\
\hline
\end{tabular}

\begin{tabular}{|l|c|c|c|c|c|c|c|c|c|c|c|}
\hline \multirow{2}{*}{ TABLE 2: Comparison of MARSA knowledge before and after the educational program among the studied subjects (N=60). } \\
\hline
\end{tabular}


Effectiveness of structured teaching programme regarding prevention and control of methicillin resistant Staphylococcus aureus on Nurses' knowledge and attitude in Egypt

\begin{tabular}{|l|c|c|c|c|}
\hline \multirow{2}{*}{ TABLE 3: Correlations between nurses' Knowledge and their demographic characteristics. } \\
\cline { 2 - 5 } & \multicolumn{2}{|c|}{ Pre-test } & \multicolumn{3}{c|}{ Post-test } \\
\cline { 2 - 5 } & $\mathrm{r}$ - / X2 value & 0.964 & $-\mathbf{X}$ value & -0.082 \\
\hline Age & $\mathrm{r}=-0.006$ & 0.193 & -0.253 & 0.532 \\
\hline Years of experience & $\mathrm{r}=0.170$ & 0.32 & 0.255 & 0.051 \\
\hline Area of work & $\mathrm{X}^{2}=0.233$ & 0.995 & 0.283 & 0.28 \\
\hline Educational level & $\mathrm{X}^{2}=0.001$ & & \\
\hline
\end{tabular}

\begin{tabular}{|c|c|c|c|c|c|c|c|c|}
\hline \multirow[t]{3}{*}{ Questions } & Pre -test & & & Post- test & & & Chi- test & \\
\hline & Agree & Disagree & neutral & Agree & Disagree & neutral & & \\
\hline & $\%$ & $\%$ & $\%$ & $\%$ & $\%$ & $\%$ & $\mathrm{x} 2$ value & p -value \\
\hline $\begin{array}{l}\text { 1- I feel with danger when contacting patients with MRSA } \\
\text { infection }\end{array}$ & & 21.7 & 11.6 & 83.3 & 15 & 1.7 & 8.355 & 0.079 \\
\hline 2- I believe I have adequate knowledge about MRSA & 16.7 & 53.3 & 30 & 75 & 20 & 5 & 5.976 & 0.042 \\
\hline $\begin{array}{l}\text { 3- I think a MRSA patient with infected wound should not be } \\
\text { allowed visitors. }\end{array}$ & 25 & 61.7 & 13.3 & 1.7 & 35 & 63.3 & 11.32 & 0.025 \\
\hline $\begin{array}{l}\text { 4-People colonized with MRSA are a danger to everyone they } \\
\text { come into contact with. }\end{array}$ & 36.7 & 46.7 & 16.6 & 63.3 & 30 & 6.7 & 9.713 & 0.00 \\
\hline $\begin{array}{l}\text { 5- I think it is beneficial to have a clear detailed leaflet including } \\
\text { specific information about MRSA }\end{array}$ & 26.7 & 56.7 & 16.6 & 55 & 43.3 & 1.7 & 38.673 & 0.00 \\
\hline $\begin{array}{l}\text { 6- Hospital staff should spend as little time as possible with } \\
\text { patients with MRSA infection }\end{array}$ & 63.3 & 21.7 & 15 & 88.3 & 11.7 & 0 & 4.808 & 0.09 \\
\hline $\begin{array}{l}\text { 7-The workload affects my ability to apply infection prevention } \\
\text { guidelines }\end{array}$ & 68.3 & 20 & 11.7 & 78.3 & 20 & 1.7 & 0.239 & 0.646 \\
\hline
\end{tabular}

nurses' attitude, the present findings revealed significant improvements in the attitude of nurses towards most of the items regarding the prevention and control of MRSA infection measures after exposure to the educational program. However, nurses showed no change in attitude after program regarding the concern of the workload affects their abilities to apply infection prevention guidelines $\left(\mathrm{X}^{2}=0.2 ; \mathrm{p}=0.6\right)$, they still feel with danger when contacting with MRSA patients $\left(\mathrm{X}^{2}=8.35 ; \mathrm{p}=0.07\right)$ and they see that they should spend little time with MRSA patient $\left(\mathrm{X}^{2}=4.8 ; \mathrm{p}=0.09\right)$ (TABLE 4).

\section{Discussion}

The study shows an overall low knowledge level among nurses in relation to MRSA infection before participation in the educational program. So, nearly two-thirds of the nurses gave incorrect answers in MRSA knowledge questionnaire regarding risk factors and prevention. Furthermore, more than half of nurses recorded false answers in the other items such as definition, methods of transmission, signs and symptoms, complications and treatment.

This finding is not surprising as previous studies were done by Lindberg M [6] who conducted a descriptive survey to investigate the knowledge of staff nurses about MRSA revealed that most of the hemodialysis nurses lacked sufficient knowledge about common sites of MRSA colonization, its prevalence, and treatment, together with infection control measures. As well, DeVoe, M [15] who studied Knowledge, perceptions, and practices of methicillin-resistant Staphylococcus aureus transmission prevention among healthcare workers in acute-care settings utilizing both survey and actual observation of clinical nursing practices revealed significant deficiencies in knowledge scores and clinical practices. Moreover, our finding is consistent with Easton et al, Da Silva, A et al , Phillips P et al , Lugg GR et al \& Askarian, M [ 11,16-19]. Who evaluated knowledge of methicillin-resistant Staphylococcus aureus and factors related to the nursing team's adherence to preventive measures revealed that nursing professionals did not know the basis of the Staphylococcus aureus' resistance to Methicillin.

On the same line, the present finding is agreed with Esther $s$ et al [14] who tested knowledge regarding predisposition to MRSA revealed that staff nurses' had limited knowledge in certain areas such as risk factors associated with MRSA. As well, more than half of responses were answered incorrectly the questions that outlined typical access sites for MRSA, surgical asepsis and highest link to MRSA outbreaks. Furthermore, Trigg D et al \& Lazzari $S$, et al $[12 \& 20]$ emphasized that if the staff do not recognize or are not aware of existing MRSA policy, MRSA would increase due to inadequate 
nurses' knowledge. The researchers postulated that a possible reason for this finding is the nurses' experiences and exposure to these issues during their undergraduate education program and more specifically during their clinical placements. Deficient knowledge could result in the provision of distorted information to patients and increase the risk of spread of organisms in care conditions (Skyman E) [21]. The need to increase healthcare personnel's knowledge level regarding MRSA is also highlighted by Brady, $\mathrm{R}$ et al [22] Furthermore, international results on healthcare personnel's knowledge of MRSA and necessary precautions when caring for patients with MRSA have revealed similar deficiencies (Easton, B et al., Phillips P et al., Gill J et al \& Burkitt k et al ) [11,17,23,24].

On the other hand, our study findings contradicted with the similar study done by Suss, $2017\{25\}$ who studied Nurses' Knowledge, Attitude, and Compliance related to Methicillin-Resistant Staphylococcus aureus in Mississippi found that overall, nurses had average knowledge of MRSA and its properties except for treatment of MRSA. Similarly, the current finding is inconsistent with a similar study done by Phillips $P$ et al $\{17\}$ who studied knowledge, attitude and perceived barriers on the care of patients with MRSA among staff nurses at a regional hospital in Trinidad revealed that staff nurses have a good overall knowledge of the pathogenesis of MRSA. As well, another study was done by Burkitt $\mathrm{k}$ et al \& Abdelsalam, $\mathrm{N}$, et al $\{24,26\}$ who revealed that most nurses were highly knowledgeable about MRSA.

Regarding the nurses' knowledge level after exposure to the educational program, our findings revealed significant improvement in nurses' total and subtotal knowledge scores. Our finding is agreed with Koltes LA $\{27\}$ who conducted an interventional study among healthcare workers of surgical ICU at Zagazig University Hospital in Egypt and found that total knowledge score was significantly increased in nurses after interventional education program. As well, Phillips P [17] emphasized that the health care workers who receive regular education and training may have a greater knowledge and positive attitude relating to MRSA. Furthermore, Abdelsalam, $\mathrm{N}$ et al $\{26\}$ instituted education programs targeting gaps in knowledge to improve MRSA prevention practices. After education, knowledge scores increased from a mean of 3.52 at baseline to 3.64.

Regarding the evaluation of nurses' attitude before exposure to the educational program, the current study revealed that $63.3 \%$ and $68.3 \%$ respectively) perceive negative attitude towards patients infected with MRSA. So, the nurses perceive that they should spend as little time as possible with patients with MRSA infection and the workload affects their abilities to apply infection prevention guidelines. Despite some negative feelings towards MRSA, two-thirds of nurses were found to have a positive attitude such as refusing the belief that MRSA patient with infected wound should not be allowed visitors and nearly half of them disagree that People colonized with MRSA are a danger to everyone they come into contact with. And more than half of nurses think that it is beneficial to have a clear detailed leaflet including specific information about MRSA. Our findings are consistent with a similar study done by Seibert $\mathrm{D}$, et al $\{10\}$ where they noted that less than half of health care professionals perceived that MRSA was a problem in their workplace or worried about transferring MRSA from the hospital to home. As well, most of them had the perception that they are not at risk because they believe that MRSA organisms die quickly in the environment. On the other hand, our finding contradicted with a Previous study done by Koltes LA \& Wolf R $\{27 \& 28\}$ who revealed that their nurses agreed that MRSA is a risk for patients who found that healthcare workers who believe that MRSA causes severe illness to engage in better preventive behaviors.

Similarly, a study researched by Philip P $\{17\}$ revealed almost half of the nurses agreed that having a patient with MRSA makes their job more difficult. As well, In study, nurses were fearful of becoming infected. Moreover, the majority of the nurses believed that infected patients should only be treated at specialized centers (Koltes LA, Wolf R \& Paudyal, P) [2729].

Regarding evaluation of nurses' attitude after application of the educational program, Nurses' attitudes toward patients with MRSA were overall more positive than before joining to the educational program except for the same points of concern about feeling with danger when contacting patients with MRSA infection, spending as little time as possible with patients 
with MRSA infection and the workload affects their abilities to apply infection prevention guidelines. The possible rationale for this finding may be interpreted in light of Canin SRMS, et al., Balbale S, et al.\& Bush-Knapp, M E [3032] point of view who stated that traditional training program can transfer knowledge but not necessarily affect change of attitude. Thus, healthcare settings should innovate strategies that capable of modifying nurses' perception of vulnerability and accordingly reinforce them to select preventive measures appropriately.

The present finding is supported and reinforced by Balbale $S$ [31] who demonstrated that to ensure proper implementation of MRSA infection prevention and control guidelines, they are in need for systematic provider education that provides evidence-based guidelines dissemination in all healthcare settings, frequent and, strong support from nursing and medical administrators that addressing barriers to fulfill guidelines and recommendations. It is also important for the researchers to explore nurses' socio-demographic data. It gives a comprehensive overview of the differences in socio-demographic characteristics such as age, gender, education, working experience in relation to MRSA knowledge. The current findings revealed no correlations what so ever between nurses' demographic characteristics and knowledge regarding MRSA. The possible explanation for this finding may have interpreted in light of Bush-Knapp, M E \{32 \} point of view that stated nurses' knowledge gained is dependent on the individual's differences and learning styles attributed to variations in hospital environments, educational programs, and pace of learning.

Contradicting to our findings, Esther, S [14] revealed a positive highest correlation between staff nurses' years of experience in relation to their level of knowledge. Therefore, it can be deduced that the years of experience in nursing positively correlates to an increased knowledge score on MRSA. As well, the highest knowledge scores were reported where staff nurses' education is within the registered nurses and MSc. Furthermore, the previous study done by Abdelsalam NM $\{26\}$ revealed that staff nurses who work within the surgical wards have a better overall knowledge of MRSA when compared to the staff nurses working in medical wards. As well, in another study conducted in the UK in 2009, researchers evaluated the knowledge levels with MRSA practice guidelines and found a correlation between the level of knowledge in regard to MRSA precautions and the specialty of the healthcare workers (Gill J) [23]. According to Fadeyi A et al [33], nurses' MRSA knowledge correlated positively with age, a number of years in service, and the number of years in the critical care unit.

\section{Limitations}

Nurses were sampled from the same university hospital.

\section{Conclusion}

There was an improvement in nurses' knowledge and attitude responses regarding MRSA control and prevention after exposure to the educational programme. Moreover, the current findings revealed no correlations what so ever between nurses' characteristics and knowledge regarding MRSA.

\section{Recommendation}

Strategies to improve attitude and compliance could be evaluated.-

- More research should be done to investigate the barriers and the impact of nursing workload on MRSA infection and prevention

-More research studies should be recommended to investigate the correlations between nurses' characteristics and their knowledge regarding MRSA.

-Develop and implement nurses' practical guidelines to prevent and control MRSA infection in a different health care setting.

\section{Acknowledgment}

The authors would like to express their sincere gratitude to all nurses participate within the current study for cooperation throughout the study period. The authors would like to express their deepest gratitude and appreciation to Dr. Dalia Safey Eldin, a nurse manager at Al Manial University Hospital for her effort in organization and cooperation to facilitate data collection process to fulfill this study. 


\section{References}

Centers for Disease Control and Prevention (CDC) (2015): Methicillinresistant - Staphylococcus aureus (MRSA) infections. CDC. Available at:

\section{.http://www.cdc.gov/mrsa}

Banning M. Transmission and epidemiology of MRSA: Current perspectives. Br. J. Nurs. 14(10), 548-554 (2005).

Su CH, Chang SC, Yan JJ, Tseng $\mathrm{SH}$, Chien LJ, Fang CT. Excess mortality and long-term disability from healthcareassociated Staphylococcus aureus infections: a population-based matched cohort study. PLoS One. 8(8), e71055 (2013).

Biboh $\mathrm{H}$. An analysis of a questionnaire survey of healthcare workers' (HCWs) knowledge on Methicillin-resistant Staphylococcus aureus (MRSA) Prevention guidelines at Oslo University Hospital. 1, 82 (2012).

Gould D. MRSA: implications for hospitals and nursing homes. Nurs. Stand. 25(18), 47-56 (2011).

Lindberg M. Haemodialysis nurses knowledge about methicillin-resistant Staphylococcus aureus. J. Ren. Care. 38 (2), 82-85 (2012).

Matouskova I, Janout V. Current knowledge of methicillin-resistant Staphylococcus aureus and communityassociated methicillin-resistant Staphylococcus aureus. Biomed. Pap. Med. Fac. Univ. Palacky Olomouc Czech Repub. 152(2), 191-202 (2008).

World Health Organization. (2009). A guide to the implementation of the WHO multimodal hand hygiene improvement strategy. Available from: http://www.who. int/gps.

Rohde RE, Rowder C, Patterson T, Redwine G, Vásquez B, Carranco E. Methicillin-resistant Staphylococcus aureus (MRSA): an interim report of carriage and conversion rates in nursing students. Clin. Lab. Sci. 25(2), 94-101 (2012).

Seibert DJ, Speroni KG, Oh KM, DeVoe MC, Jacobsen KH. Knowledge, perceptions, and practices of methicillinresistant Staphylococcus aureus transmission prevention among healthcare workers in acute-care settings. Am. J. Infect. Control. 42(3), 254-259 (2014).

Easton PM, Sarma A, Williams FL, Marwick CA, Phillips G, Nathwani D. Infection control and management of MRSA. J. Hosp. Infect. 66(1), 29-33 (2007).

Trigg D, Timmons S, Pynegar C. An audit of healthcare workers' knowledge of meticillin-resistant Staphylococcus aureus (MRSA) against current infection control standards. Br. J. Infect. Contr. 9(1), 30-33 (2008).

Klein, E., Smith, Gould, D. (2011). MRSA: implications for hospitals and nursing homes. Nursing Standard, 25(18), 47-56.

Esther S, Daniel, Ruhee M. Knowledge, attitude and perceived barriers on the care of patients with methicillinresistant Staphylococcus aureus (MRSA), among staff nurses at a regional hospital, trinidad. Int. J. Adv. Res. 5(4), 1183-1195 (2017).

DeVoe, M. C. (2014). Knowledge, perceptions, and practices of MethicillinResistant Staphylococcus Aureus transmission prevention among healthcare workers in acute-care settings. American Journal of Infection Control, 42, 254-9.

16-Da Silva AM, De Carvalho MJ, Da Silva Canini SR, De Almeida Cruz ED, Simōes CL, Gir E. Methicillin-Resistant Staphylococcus aureus: Knowledge and factors related to the nursing teams adherence to the preventive measures. Rev. Lat. Am. Enfermagem. 18(3), 346-51 (2010).

Phillips PS, Golagani AK, Malik A, Payne FB. A staff questionnaire study of MRSA infection on ENT and general surgical wards. Eur. Arch. Otorhinolaryngol. 267(9), 1455-1459 (2010).

Lugg GR, Ahmed HA. Nurses' perceptions of methicillin-resistant Staphylococcus aureus: Impacts on practice. Br. J. Infect. Contr. 9(1), 8-14 (2008).

Askarian M, Shiraly R, McLaws ML.
Knowledge, attitude and, and practices of contact precautions among Iranian nurses. Am. J. Infect. Control. 33(8), 486-488 (2005).

Lazzari S, Allegranzi B, Concia E. Making hospitals safer: the need for a global strategy for infection control in healthcare settings. World Hosp. Health Serv. 40(2), 32-42 (2004).

Skyman E, Sjöström HT, Hellström L. Patients' experiences of being infected with MRSA at a hospital and subsequently source isolated. Scand. J. Caring. Sci. 24(1), 101-107 (2010).

Brady RR, McDermott C, Cameron F, Graham C, Gibb AP. Health care workers knowledge of Methicillin-Resistant Staphylococcus aureus practice guidelines; A questionnaire study. J. Hosp. Infect. 73(3), 264-270 (2009).

Gill J, Kumar R, Todd J, Wiskin C. Methicillin-Resistant Staphylococcus aureus: Awareness and perception. J. Hosp. Infect. 62(3), 333-7 (2006).

Burkitt KH, Sinkowitz Cochran RL, Obrosky DS, Cuerdon T, Miller LJ, Jain R, et al. Survey of employee knowledge and attitudes before and after a multicenter Veterans' Administration quality improvement initiative to reduce nosocomial methicillin-resistant Staphylococcus aureus infections. Am. J. Infect. Control. 38(4), 274-282 (2010).

Suess,E.Nurse Knowledge, Attitude, and Compliance Related to Methicillin Resistant Staphylococcus aureus. A Thesis Submitted to Honors College of The University of Southern Mississippi ( 2017).

Abdelsalam NM, Bakry HM, Bolbol SA, Abdelsalam AE, Atef DM. MethicillinResistant Staphylococcus Aureus: An interventional study among healthcare workers of surgical ICU at Zagazig University Hospital, Egypt. EJOM. 41(1), 97-113 (2017).

Koltes LA. Healthcare workers'attitudes, understanding and perceived risk of methicillin-resistant Staphylococcus aureus [dissertation]. Fargo (ND): North Dakota State University (2009). 
Wolf R, Lewis D, Cochran R, Richards C. Nursing staff perceptions of methicillin-resistant Staphylococcus aureus and infection control in a longterm care facility. J. Am. Med. Dir. Assoc. 9(5), 342-346 (2008).

Paudyal P, Simkhada P, Bruce J. Infection control knowledge, attitude,
and practice among Nepalese healthcare workers. Am. J. Infect. Control. 36(8), 595597 (2008).

Canini SRMS, Moraes AS, Gir E, Freitas ICM. Fators associated with percutaneous accidents in the nursing team of a university tertiary level hospital. Rev. Latino Am. Enfermagem. 16(5), 818823 (2008).

Balbale SN, Hill JN, Guihan M, Hogan TP, Cameron KA, Goldstein B Evaluating implementation of methicillinresistant Staphylococcus aureus (MRSA) prevention guidelines in spinal cord injury centers using the PARIHS framework: a mixed methods study. Implement Sci. 10, 130 (2015).

Bush Knapp ME, Brinsley Rainisch
KJ, Lawton Ciccarone RM, Sinkowitz Cochran RL, Dressler DD, Budnitz T. Spreading the word, not the infection: Reaching hospitalists about the prevention of antimicrobial resistance. Am. J. Infect. Control. 35(10), 656-661 (2007).

Fadeyi A, Adeboye MA, Fowotade A, Nwabuisi C, Bolaji BO, Oyedepo OO, et al. Methicillin-resistant Staphylococcus aureus: Awareness, knowledge, and disposition to screening among health care workers in critical care units of a Nigerian Hospital. West Afr J Med. 30(4), 282-287 (2011). 